\title{
Correspondence
}

\section{Home Secretary's comments on the Stone case}

Sir: I was dismayed by the Home Secretary's comments on the Stone case on BBC Radio 4 on the 27 October 1998. He told the radio audience that psychiatrists get caught up in the "intellectual" trap of not forcing treatment on antisocial personality disorders by using the feeble excuse that these patients are untreatable. He added that psychiatrists are only likely to act when the individual commits a serious crime, implying perhaps that we should be more proactive and incarcerate the person at the earliest opportunity. He finally declared that if psychiatrists are unable to treat people with these diagnoses, perhaps other disciplines could help, ignoring the existence of multi-disciplinary work in mental health.

This type of populistic reaction to a tragedy is unhelpful. A horrific crime is being portrayed by the Government as a mental health failure, even if the perpetrator was not mentally ill. The "lock them all up" concept is simplistic, unworkable. certainly illegal, and probably undesirable. We should actively reject our increasingly custodial role and the idea that psychiatry is primarily about containing dangerousness, and that therefore dangerousness must be in itself a psychiatric responsibility.

Rafael Euba, Consultant Psychiatrist, Memorial Hospital, Shooters' Hill, London SE18 3RZ

\section{MHRT medical reports}

Sir: Ismail et al (Psychiatric Bulletin, October $1998,22,615-618$ ) have produced a study of 100 consecutive mental health review tribunal reports in an attempt to discover what proportion satisfy the criteria for detention in accordance with the Mental Health Act 1983. This is an important issue that will aid the tribunal process and, therefore, deserves wider recognition.

However, the authors have themselves been guilty of a small but fundamental error that also plagues many MHRT reports. They state under criterion (c) "Is the mental disorder of such a nature and degree ...". Of course, the wording of the Act is nature or degree and there is some legal difference between the two. The word 'and' implies that both must be present while 'or' gives rise to a different meaning entirely, that is either nature or degree is sufficient in themselves. Is this distinction important you may ask? Consider the case of depression. How severe must it be before it constitutes a mental illness for the purpose of the Act? All individuals suffer some feelings of depression at some point in their lives but for the majority this is not considered abnormal. The nature of the illness is not what is the issue in this example, it is the degree. That is why they remain separate and to use them mutually is more than just a typographical error, it is not the law.

ERnest Gralton, Specialist Registrar in Forensic Psychiatry, and STEPHEN PEARSON, Senior House Officer in Psychiatry, Langdon Hospital, Dawlish, Devon EX7 ONR

\section{CPD: monitoring attendance or measuring performance?}

"Not everything that counts can be counted and not everything that can be counted counts" (Cameron. 1963).

Sir: The only conclusion that one makes looking at the College Continuing Professional Development (CPD) logbook is that a consultant has managed to attend a certain number of meetings covering various CPD models. This does not indicate whether this consultant has or has not continued to develop professionally as the CPD implies. The question that should be addressed is: What value or benefit has the frequent attendance of CPD meetings made to the service and patient's care?

A good proportion of CPD meetings that psychiatrists attend, with the exception of very few international and national conferences, are essentially pharmaceutical mini-breaks, usually in Europe or some exotic place. To attend such meetings, doctors are almost certainly paid by drug companies with an inevitable. subtle or obvious, promotional component for their products, especially the new, expensive, psychotropics.

It is now time to have a look at the current CPD in order to accommodate a system of periodic assessment of doctors. A system that encourages doctors to respect changes and integrate into practice innovations that are shown to enhance patient care. The traditional continuing medical education and professional development, that update doctors' knowledge, should be replaced by a system that ensures 'actual' professional 